\title{
EVALUATION OF DIMENSIONAL STABILITY, SURFACE ROUGHNESS, COLOUR, FLEXURAL PROPERTIES AND DECAY RESISTANCE OF THERMALLY MODIFIED Acacia auriculiformis
}

\author{
S.R. Shukla ${ }^{1,4}$
}

\begin{abstract}
This paper presents the effect of thermal modification of 14-15 year-old plantation grown Acacia auriculiformis wood in the $150-240^{\circ} \mathrm{C}$ temperature range under vacuum condition. Important techno-mechanical parameters of thermally modified wood such as density, dimensional stability, colour, surface roughness, decay resistance against brown and white rot fungi and flexural properties were evaluated and compared with control. Depending on severity of heat treatment, colour of modified sapwood was turned from light to dark brownish. Moreover, the change in colour was found to be uniform throughout the thickness of wood blocks. Amount of shrinkage of Acacia auriculiformis wood was observed to be decreased with increasing treatment temperatures. Maximum dimensional stability of wood thermally modified at $240^{\circ} \mathrm{C}$ was in the range of $60-65 \%$. The surface roughness parameters $\left(\mathrm{R}_{\mathrm{a}}\right.$ and $\left.\mathrm{R}_{\mathrm{z}}\right)$ were reduced significantly after the treatment. The flexural strength (modulus of rupture-MOR) was observed to be reduced with increasing treatment temperatures. However, flexural stiffness (modulus of elasticity-MOE) was not found to be affected significantly up to $210^{\circ} \mathrm{C}$ temperature. The lower amount of weight loss of thermally modified wood compared to untreated control showed improved decay resistance against white and brown rot fungi. With desirable improvements in various esthetic and technologically important quality parameters such as enhanced dimensional stability, biological durability against fungi and certain other properties, thermally modified wood from short-rotation Acacia auriculiformis may be considered as viable alternative to scarcely available timber resource for different value-added applications.
\end{abstract}

Keywords: Density, heat treatment, MOR, MOE, plantation species, shrinkage.

\section{INTRODUCTION}

Because of the rapid industrialization and increasing population, forest wealth is depleting at a rapid rate. Thus, it has become imperative to make use of fast grown plantation species for various timber applications. But, most of fast growing plantation speciesgenerally contains a high proportion of juvenile wood. The wood of such species is often characterized by certain inherent material problems such as low dimensional stability, low mechanical properties and poor decay resistance against bio-deteriorating agents. These are mostly accepted as undesirable features for many timber applications. Selection of decay resistant and dimensionally stable wood species for a specific use, therefore, plays an important role in achieving its most economic utilization. Moreover, efficient usage of locally grown wood resource from plantations as a source of raw material is very important for growth of wood-based industry. In order to overcome one or more limitations, wood material is generally modified by thermal or chemical techniques so as to improve certain quality parameters specific to various end-use requirements (Gerardin 2016, Hill 2006, Rep and Pohleven 2001). Thermal modification

\footnotetext{
${ }^{1}$ Wood Properties and Uses Division, Institute of Wood Science and Technology,

P.O. Malleswram, Bangalore, India.

•Corresponding author: srshukla@icfre.org

Received: 09.11.2018 Accepted: 24.05.2019
} 
of wood is mostly performed at higher temperatures (below $250^{\circ} \mathrm{C}$ ) depending on the required level of product performance and species. Heat treatment process is found to provide wood with certain novel properties by changing its behavior (Bakar et al. 2013, Esteves and Pereira 2009, Niemz and Bekhta 2003). Moreover, changes in wood characteristics are achieved without adding toxic chemicals/preservatives. Thermally modified wood exhibits improved performance and provide value-addition to traditionally poor quality woods as a substitute for certain high value tropical species (Kim et al. 1998, Shukla and Sharma 2014, Shukla and Sharma 2018). Many fast grown plantation woods having lower commercial value can be thermally modified so as to become new source of raw material for the timber industry. At the same time, this process also has huge growth potential due to gradual banning of chemically treated wood for environmental reasons (Gerardin 2016).

Acacia auriculiformis from Leguminosae family is a fast-growing medium sized tree native to coastal lowlands of Northern Australia, Papua and New Guinea. Because of its ability to grow on very poor soil and in areas with an extended dry season, it has been introduced into countries such as India, Indonesia, Malaysia, Tanzania and Nigeria. Initially, this species was grown in India to meet the demand of pulp and fire wood. It is mostly raised in plantation forestry under many afforestation programmes in the country and also planted in agro-fields, as well as shelter and ornamental tree.Detailed studies on various physical and mechanical properties of $A$. auriculiformis woodhave showed that this timber can be utilized for joinery, tool handles, turnery articles and for construction purposes (Shukla et al. 2007). One of the most important drawbacks of wood from this species is its lower dimensional stability (Shukla et al. 2007) and low durability of sapwood (Ashaduzzaman et al. 2011, Sundararaj et al. 2015). The natural decay resistance of A. auriculiformis was evaluated by accelerated decay test method against white rot fungus. The average weight loss in sapwood was found to be 22,19\% (Ashaduzzaman et al. 2011) which is considered to be not durable and require treatments to improve the service life.

The fast grown plantation timbers may be subjected to thermal modification at high temperatures under inert environment to improve the dimensional stability, colour and decay resistance. This process is expected to open up certain potential applications taking advantage of the chemical free process. Various chemical changes occurring during thermal treatment invariably lead to the alteration in various wood properties (Esteves and Pereira 2009, Kamdem et al. 2000, Kamdem et al. 2002, Obataya and Tomita 2002). The effect of steam pretreatment on wood was investigated by various researchers (Inoue et al. 1993, Inoue et al. 1996, Kawai et al.1992). The effect of heat on dimensional stability of compressed wood is reported by Dwianto et al. (1996) while thermo-hygro-mechanical treatment for producing densified wood with stable deformation was carried out by Navi and Girardet (2000). During heat treatment, there are considerable changes in chemical composition of wood (Hofmann et al. 2008). Various chemical changes invariably lead to the alteration of various physical properties of wood (Obataya et al. 2000, Obataya and Tomita 2002). Repellin and Guyonnet (2005) investigated the effect of treatment temperature and duration on swelling behavior of heat-treated wood. Not much research work is reported in the literature on effect of heat treatment of $A$. auriculiformison various wood properties. The aim of the present study was to investigate the effect of heat treatments of $A$. auriculiformis wood at different temperatures under vacuum on certain important quality parameters such as density, shrinkage, colour, surface roughness, decay resistance against brown and white rot fungi and flexural properties. The improved characteristics of thermally modified wood are expected to offer the timber industry an alternate timber resource for producing various value-added wood products.

\section{MATERIALS AND METHODS}

\section{Wood}

Ten logs of plantation grown14-15 year-old Acacia auriculiformis A. Cunn. Ex. Benth trees were selected for processing and converted into thirty wooden planks of the size 1,8-2,4 m length, $15-25 \mathrm{~cm}$ width and $5,0-7,5 \mathrm{~cm}$ thickness. The planks were stacked for drying under the shade having good ventilation for about 6 months to obtain the equilibrium moisture content (EMC) in the range $10 \pm 3 \%$. The seasoned material was used for further conversion and processing into test specimens of different sizes as specified in Indian standards (IS 1708-1986). 


\section{Heat treatment}

Heat treatment was carried out by in a microprocessor controlled camber. Three steel meshes were used in which the wood samples were placed inside the oven. For an $8 \mathrm{~h}$ heat treatment, total cycle was about $48 \mathrm{~h}$ including initial heating ramp of about $8 \mathrm{~h}$, conditioning at $105^{\circ} \mathrm{C}$ for about $10 \mathrm{~h}$ followed by ramping to actual target temperature in about $15 \mathrm{~h}$ and finally cooling down slowly in about $15 \mathrm{~h}$. All the heating and cooling processes were carried out inside an oven under vacuum (below 10 milli bar). During actual heat treatment phase, temperature was increased to desired level between 150 to $240^{\circ} \mathrm{C}$ and remained constant for duration up to a maximum of $8 \mathrm{~h}$. Conditioning of treated wood samples was carried out at $23 \pm 3^{\circ} \mathrm{C}$ temperature and $65 \pm 5 \%$ relative humidity in a conditioning chamber to bring them to equilibrium moisture level.

\section{Testing of properties}

The test samples of untreated control and heat treated wood species were prepared and different physical, mechanical and biological properties were tested. Volumetric shrinkage and flexural properties were evaluated following standard procedures as laid down in IS1708- 1986. Flexural tests were performed on a 50kN capacity universal testing machine (Shimadzu AG-50) installed in a conditioning chamber set at $23 \pm 3^{\circ} \mathrm{C}$ temperature and $65 \pm 5 \%$ relative humidity. Following procedures were adopted for various tests.

\section{Density}

The specimen size was $2 \times 2 \mathrm{~cm}^{2}$ in cross-section and $6 \mathrm{~cm}$ in length. Eight specimens of each heat treatment and untreated control wood were weighed correctly to $0,001 \mathrm{~g}$ and dimensions were measured correctly to $0,01 \mathrm{~mm}$. Density (D) of wood specimens was calculated using the following Equation 1:

$$
D=W / V
$$

Where $\mathrm{W}$ and $\mathrm{V}$ are weight $(\mathrm{kg})$ and volume $\left(\mathrm{m}^{3}\right)$ of test specimen respectively.

\section{Volumetric shrinkage}

Test specimens were $2 \times 2 \mathrm{~cm}^{2}$ in cross-section and $6 \mathrm{~cm}$ in length. Six specimens from each treatment were weighed initially correctly to $0,01 \mathrm{~g}$ and volume was determined by immersion method. Specimens were allowed to air-dry and weighed periodically, then kept in an oven at $103 \pm 2{ }^{\circ} \mathrm{C}$ until an approximately constant weight is reached. After oven-drying, specimens were weighed and volumes were determined again. Volumetric shrinkage (S) from initial condition to oven-dry condition is computed as follows Equation 2a:

$$
\mathrm{S}(\%)=\left(\left(\mathrm{V}_{1}-\mathrm{V}_{0}\right) / \mathrm{V}_{1}\right) \times 100
$$

Where $\mathrm{V}_{1}=$ volume in cc at initial condition (usually green), $\mathrm{V}_{0}=$ volume in $\mathrm{cc}$ at the oven dry condition. The anti-shrinkage efficiency (ASE) was computed using average total volumetric shrinkage of untreated $\left(\mathrm{S}_{1}\right)$ and treated $\left(\mathrm{S}_{2}\right)$ wood samples using following Equation $2 \mathrm{~b}$ :

$$
\operatorname{ASE}(\%)=\frac{S_{1}-S_{2}}{S_{1}} \times 100
$$

\section{Surface roughness}

Effect of thermal modification of wood at different temperatures under vacuum was studied on the surface properties. Surface roughness profile of A. auriculiformis wood was measured using a stylus-based profilo- 
meter (Mitutoyo Surftest SJ-401) before and after heat treatments (Shukla and Sharma 2014). The measuring speed, pin diameter, and pin top angle of the tool were $10 \mathrm{~mm} / \mathrm{min}, 4 \mu \mathrm{m}$, and $90^{\circ}$ respectively. Five to six points of roughness measurement were randomly marked on the surface of three wood samples from each treatment. Measurements were carried out in the fiber direction (along) and in perpendicular to the fiber direction (across). Two roughness parameters viz., arithmetical mean roughness $\left(\mathrm{R}_{\mathrm{a}}\right)$ which is average distance from the profile to the mean line over the length of assessment and mean roughness $\left(R_{z}\right)$ were used to evaluate surface roughness characteristics of heat treated wood.

\section{Surface colour}

The LabScan XE system (Model: LSXE-2, LSXE/VSI-2) from Hunter Associates Laboratory, Inc., Virginia was used for measuring colour parameters (L, a, b) in a wavelength range of 400-700 nm. In CIELab system, total change of color, $\Delta \mathrm{E}^{*}$, is commonly used to represent a color difference: $\Delta L^{*}$ is difference in lightness $\mathrm{L}^{*}-\mathrm{L}^{*}{ }_{\text {control }}, \Delta \mathrm{a}^{*}$ is difference in $\mathrm{a}^{*}$ coordinates $\mathrm{a}^{*} \mathrm{a}^{*}{ }_{\text {control }}, \Delta \mathrm{b}^{*}$ is difference in $\mathrm{b}^{*}$ coordinates $\mathrm{b}^{*} \mathrm{~b}^{*}$ control where $\mathrm{L}^{*}{ }_{\text {control }}, \mathrm{a}^{*}{ }_{\text {control }}$ and $\mathrm{b}^{*}$ control are mean values of these colour components for untreated control sets, and $\mathrm{L}^{*}, \mathrm{a}^{*}$ and $b^{*}$ are colour variables of each treated specimen. For maximum stability, the instrument was standardized to an internal reference tile once every $4-5 \mathrm{~h}$ during color measurements. Before and after heat treatment, $\mathrm{L}^{*}$, $\mathrm{a}^{*}$ and $\mathrm{b}^{*}$ color coordinates of each sample were used to calculate total colour change according to following Equation $3 a$ and Equation $3 b$ :

$$
\begin{gathered}
\Delta L^{*}=L_{h t}^{*}-L_{i}^{*} ; \Delta a^{*}=a^{*}{ }_{h t}-a_{i}^{*} ; \Delta b^{*}=b_{h t}^{*}-b_{i}^{*} \\
\Delta E=\left(\Delta L^{* 2}+\Delta a^{*^{2}}+\Delta b^{* 2}\right)^{1 / 2}
\end{gathered}
$$

Where $\Delta \mathrm{L}^{*}, \Delta \mathrm{a}^{*}, \Delta \mathrm{b}^{*}$ are changes between untreated and treated values. $\mathrm{L}^{*}, \mathrm{a}^{*}, \mathrm{~b}^{*}$ contribute to total color change $\Delta \mathrm{E}$.

\section{Flexural properties}

For flexural properties (3-point static bending test), 20 specimens of the size $2 \times 2 \times 30 \mathrm{~cm}^{3}$ were selected as specified in IS:1708-1986 from each treatment. The span length and rate of loading was kept constant at 28,0 $\mathrm{cm}$ and $1,0 \mathrm{~mm} / \mathrm{min}$ respectively. Load was applied on tangential surface nearer to heart of each specimen. Two different flexural parameters: modulus of rupture (MOR) and modulus of elasticity (MOE) were computed using following Equation $4 \mathrm{a}$ and Equation $4 \mathrm{~b}$ :

$$
\begin{gathered}
\operatorname{MOR}=\left(3 \times \mathrm{P}_{\max } \times 1\right) /\left(2 \times \mathrm{b} \times \mathrm{h}^{2}\right) \\
\operatorname{MOE}=\left(\mathrm{P} \times \mathrm{l}^{3}\right) /\left(4 \times \mathrm{D} \times \mathrm{b} \times \mathrm{h}^{3}\right)
\end{gathered}
$$

Where:

$\mathbf{P}$ - load at the limit of proportionality $(\mathrm{kN})$

$\mathbf{P}_{\max }$ - maximum load $(\mathrm{kN})$

$\mathbf{I}$ - span of the test specimen $(\mathrm{mm})$

b - breadth of the test specimen $(\mathrm{mm})$ 
$\mathbf{h}$ - depth of the test specimen (mm)

D - deflection at the limit of proportionality (mm)

\section{Decay resistance against fungi}

Decay resistance of heat treated A. auriculiformis wood was determined against two types of fungi, viz. brown rot (Polyporus meliae) and white rot (Coriolus versicolor, also known as Trametes versicolor and Polyporus versicolor). Six small cubic blocks measuring $20 \times 20 \times 20 \mathrm{~mm}^{3}$ of control and heat treated A. auriculiformis wood were tested by adopting modified Aagar block (Kolle flask) procedure as prescribed in IS:4873 (Part-1)with a slight variation in the size of the test blocks (IS 4873-2008). A mixture of the nutrient medium consisting of agar and malt extract $(1: 1 \mathrm{wt} \%)$ was prepared in a liter of distilled water. The medium was inoculated with the test fungi within 6 days after preparation of the flasks. Test blocks were exposed to the fungal attack of brown and white rots separately by placing them in flask having actively growing cultures of two fungi. The bottles containing the test blocks were placed in an incubator at $25 \pm 1^{\circ} \mathrm{C}$ and $70 \pm 4 \%$ relative humidity and kept there for a period of 12 weeks. At the end of the incubation period, exposed blocks were removed and mycelium was cleaned properly. The blocks were then dried at $30^{\circ} \mathrm{C}$ to constant weight. Finally, weight of the blocks was recorded to determine the weight loss (WL) caused by the fungal decay Equation 5:

$$
\mathrm{WL}(\%)=\left[\left(\mathrm{W}_{\mathrm{i}}-\mathrm{W}_{\mathrm{t}}\right) / \mathrm{W}_{\mathrm{i}}\right] \times 100
$$

Where:

$$
\begin{aligned}
& \mathbf{W}_{\mathrm{i}} \text { - weight of wood block before test }(\mathrm{g}) \\
& \mathbf{W}_{\mathrm{t}} \text { - weight of dried block after test }(\mathrm{g}) \text {. }
\end{aligned}
$$

\section{Statistical analysis}

Variation in the density and flexural properties of treated and untreated wood were compared and analyzed by one-way analysis of variance (ANOVA) at the 5\% level of significance using with SigmaStat statistical software (Systat 2004).

\section{RESULTS AND DISCUSSION}

Heat treatment of wood material at high temperature causes a lot of chemical and physical changes into the wood. Certain volatile organic compounds and extractives present in the wood material get evaporated during the process of heat treatment. The change in the physical properties of wood is realized through the transformation of chemical components and through the alteration of the wood structure (Hill 2006, Hofmann et al. 2008, Niemz et al. 2010).

\section{Density and EMC}

Table 1 summarizes mean density values of wood heat treated at different temperatures under vacuum. Percentage change in density of thermally modified wood compared to untreated control showed that heat treatment temperatures up to $210^{\circ} \mathrm{C}$ did not alter it much $(7,7 \%)$. However, higher heat treatment temperature of $240^{\circ} \mathrm{C}$ caused greater reduction in the range of $14-15 \%$. Similarly, no significant variations were observed in density of wood heat treated to different durations at the same temperature for lower than $210^{\circ} \mathrm{C}$. The average EMC was also found to be strongly affected by heat treatment process. EMC of wood samples was found to be drastically reduced depending on severity of heat treatments. It was observed that heat treated $A$. auriculiformis wood has average EMC in the range of $(6 \pm 1 \%)$ compared to untreated wood $(12 \pm 1 \%)$. Reduction in the EMC 
of heat-treated wood has shown influence not only on the dimensional stability (shrinkage and swelling), but on many other important wood properties. The changes in hygroscopic properties of wood are mainly caused by degradation of hemicelluloses due to high temperature heating. During this process, the organic acid coming from hemicelluloses creates an acidic environment which is combined with high temperature to break down the lignin-polysaccharide linkages in wood structure. This process changes the wood from a hygroscopic to hydrophobic material (Wikberg and Liisa 2004). Water absorption of wood after heat treatment is thus reduced because a large number of hydroxyl groups $(-\mathrm{OH})$ of carbon-hydrogen compounds are reported to be decreased (Nakano and Miyazaki 2003).

Table 1: Density and EMC of A. auriculiformis wood heat treated at different temperatures.

\begin{tabular}{c|c|c|c|c|c}
\hline \multirow{2}{*}{ Property } & \multirow{2}{*}{ Untreated } & \multicolumn{4}{|c}{ Treatment temperatures (8h) } \\
\cline { 3 - 6 } & wood & $\mathbf{1 5 0}^{\circ} \mathbf{C}$ & $\mathbf{1 8 0}^{\circ} \mathbf{C}$ & $\mathbf{2 1 0}^{\circ} \mathbf{C}$ & $\mathbf{2 4 0}^{\circ} \mathbf{C}$ \\
\hline \multirow{2}{*}{ Density $\left(\mathrm{kg} / \mathrm{m}^{3}\right)$} & $702,80 \pm$ & $671,81 \pm$ & $657,74 \pm$ & $648,48 \pm$ & $599,58 \pm$ \\
& $64,83^{\mathrm{a}}$ & $77,03^{\mathrm{ab}}$ & $67,78^{\mathrm{b}}$ & $72,43^{\mathrm{b}}$ & $56,10^{\mathrm{c}}$ \\
\hline \% Change & - & 4,41 & 6,41 & 7,73 & 14,69 \\
\hline \multirow{2}{*}{ EMC (\%) } & $11,80 \pm$ & $7,29 \pm$ & $6,93 \pm$ & $4,94 \pm$ & $4,57 \pm$ \\
& $0,82^{\mathrm{a}}$ & $0,63 \mathrm{~b}$ & $1,12^{\mathrm{b}}$ & $0,58^{\mathrm{c}}$ & $0,43^{\mathrm{c}}$ \\
\hline \% Change & - & 38,2 & 41,3 & 58,2 & 61,3 \\
\hline
\end{tabular}

Mean values ( \pm standard deviations) in the same row followed by the identical letters are not statistically significantly different at level of 5\%, Tukey Test).

\section{Dimensional stability}

Real-time tangential swelling profile of A. auriculiformis wood heat treated in vacuum for $8 \mathrm{~h}$ at different temperatures is shown in Figure 1. Wood sample starts swelling first at higher rate and then slowly levels-off to certain value. The rate of swelling was found to decrease with increasing heat treatment temperature of wood. Total tangential swelling of untreated control wood was highest and heat treatments of wood systematically reduced the amount of total saturated swelling as shown in the real-time graph. Similarly, volumetric shrinkage was found to be reduced with increasing treatment temperature. A linear relationship of the form: $\mathrm{S}=(-) 0,06 \mathrm{~T}+17,92\left(\mathrm{R}^{2}=0,98\right)$ was observed between volumetric shrinkage $(\mathrm{S})$ and treatment temperature $(150 \leq \mathrm{T} \leq 240)$. The percentage of reduction of total volumetric swelling of wood treated at $240^{\circ} \mathrm{C}$ was about highest compared to untreated control.

The anti-shrinkage efficiency (ASE) of A. auriculiformis wood heat treated at different temperatures for $8 \mathrm{~h}$ duration is depicted in Figure 2. The ASE values of wood were found to increase with the temperature of heat treatment. Higher treatment temperatures made the wood more dimensionally stable as shown by increasing ASE values (up to 65\%). Chu (2013) reported that the dimensional stability (anti-swelling coefficient) of Acacia mangium wood was increased by about $15-46 \%$ afterheat treatment at high temperature $\left(170-210^{\circ} \mathrm{C}\right.$.) in air. The results also indicated that both treatment temperature and treatment duration significantly affect the wood properties of this species. As explained above, heating process is known to cause various changes in the chemical structure of wood. First, hemicelluloses start to degrade resulting in the reduction of -OH bonds and formation of O-acetyl groups. With subsequent cross-linking between wood fibers, wood becomes more hydrophobic. Reduction in water absorption causes a decrease in swelling and shrinking of wood leading to improved dimensional stability. Repellin and Guyonnet (2005) also investigated the effect of treatment temperature and duration on swelling behaviour of heat-treated wood. Increased temperature and longer duration of heat treatment resulted into reduced wood swelling. Modification of cell-wall structure and changes in sorption properties due to decomposition of hydrophilic hydroxyl-groups are considered to be responsible for lower water absorption, improved dimensional stability and durability of thermally modified wood. Reduction of adsorption sites along with structural changes in process of heat modification were suggested to be responsible for reduced swelling and shrinkage of heat treated wood. Therefore, changed cell wall chemistry has been attributed to improved dimensional stability and reduced water absorption capacity of heat treated wood 
(Metsa-Kortelainen et al. 2006).

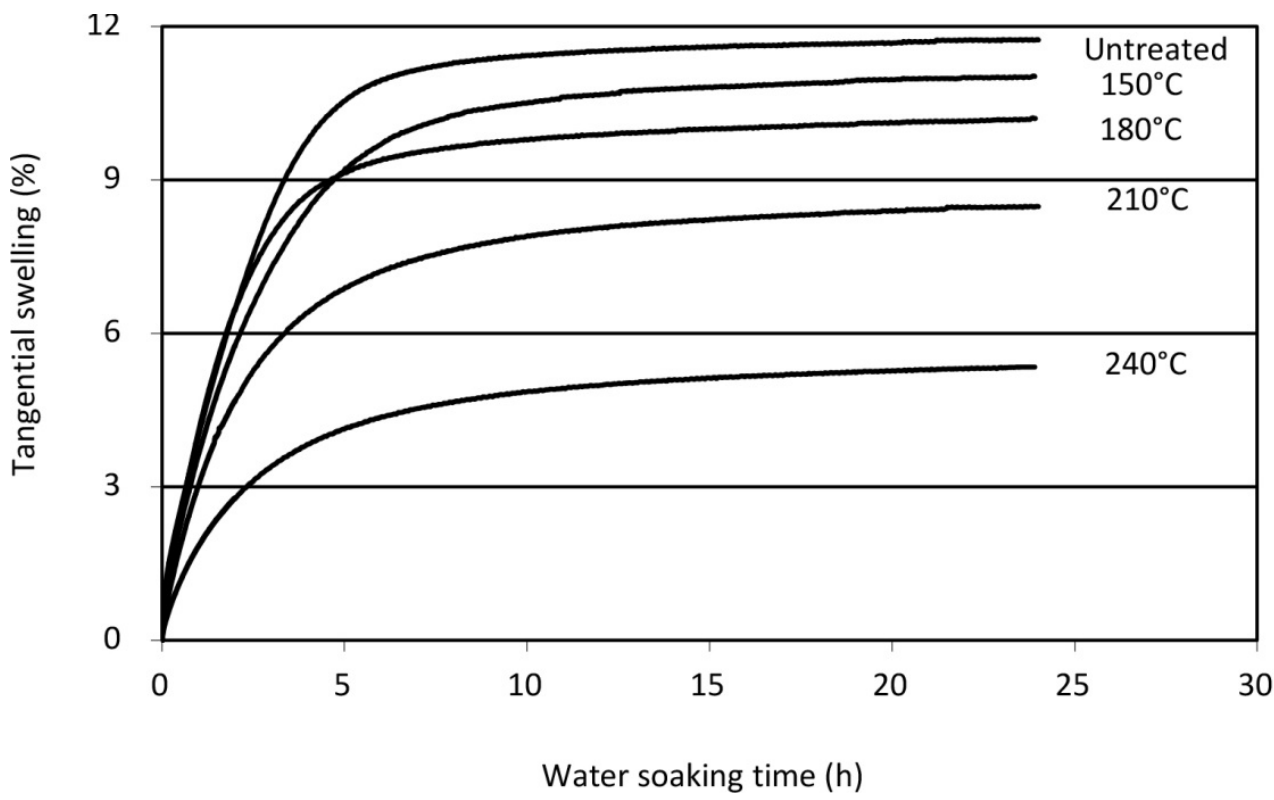

Figure 1: Real-time tangential swelling profile of heat treated A. auriculiformis wood.

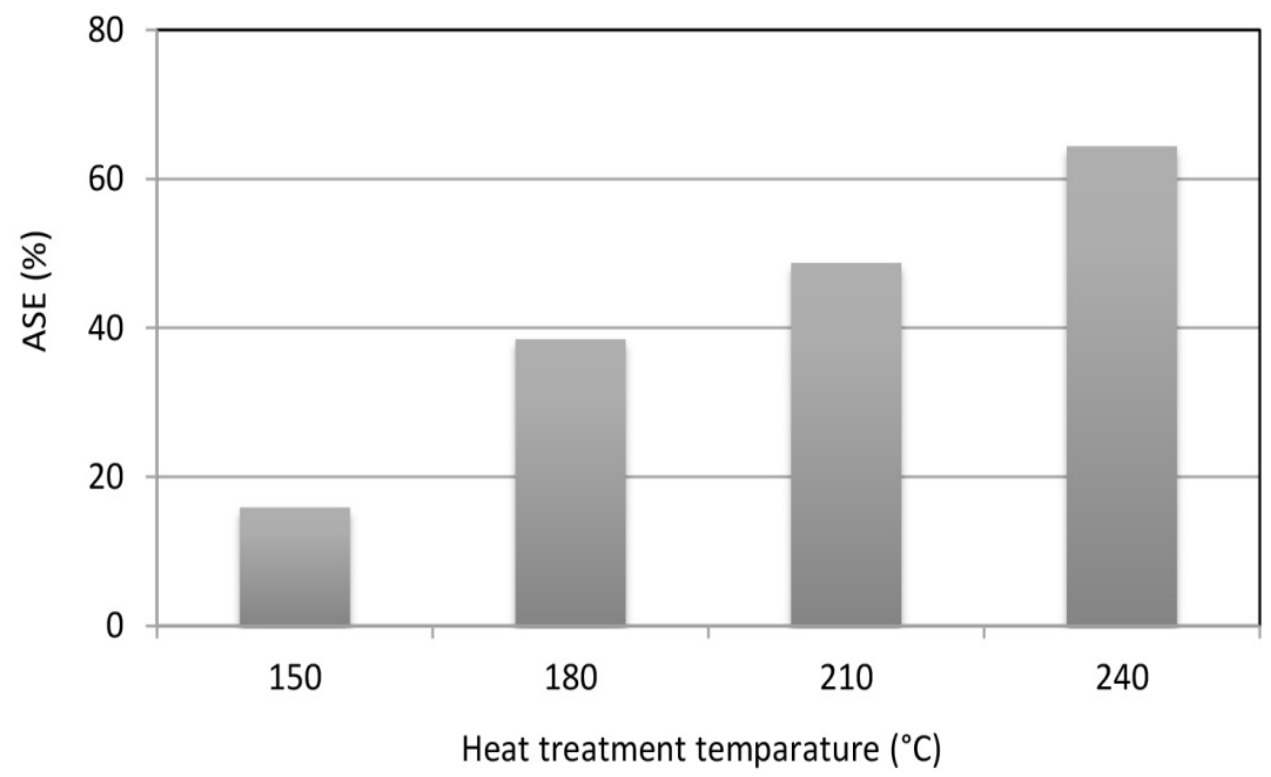

Figure 2: ASE of A. auriculiformis wood heat treated for $8 \mathrm{~h}$ at different temperatures.

\section{Surface roughness}

Figure 3a and Figure 3b show the effect of heat treatment on surface roughness profiles of wood before and after thermal modification at $180^{\circ} \mathrm{C}$ for $8 \mathrm{~h}$. Heat treated wood showed lower value of $\mathrm{R}_{\mathrm{a}}(=3,14 \mu \mathrm{m})$ compared to untreated $\left(\mathrm{R}_{\mathrm{a}}=4,54 \mu \mathrm{m}\right)$ wood samples. The results showed that surface roughness values decreased with increasing treatment temperature and duration. Figure $4 a$ and Figure $4 b$ depict average $R_{a}$ and $R_{z}$ values measured before and after heat treatments at different temperatures for $8 \mathrm{~h}$ along and across the grain on the surface of wood samples. 
The average $\mathrm{R}$ values were much lower for both along and across the grain after thermal modification of wood samples. Similarly, surface profile parameters $\left(\mathrm{R}_{\mathrm{z}}\right.$ and $\left.\mathrm{R}_{\mathrm{z}}\right)$ of wood were found to be $(5,72$ and $39,8 \mu \mathrm{m})$ and $(3,87$ and $24,5 \mu \mathrm{m})$ respectively before and after heat treatment at $180^{\circ} \mathrm{C}$ for $8 \mathrm{~h}$. These observations showed that roughness parameters of wood were much higher in the direction across the fibers compared to along the fiber. The wood surface turned smoother in both directions after heat treatments. Korkut and Akgul (2007) reported effect of high processing temperatures on surface roughness characteristics of wood veneers. It was concluded that these wood species may be utilized by using proper heat treatment techniques in areas where working, stability, and surface smoothness are important factors such as in floorings, furniture, window frames (Gunduz et al. 2008).
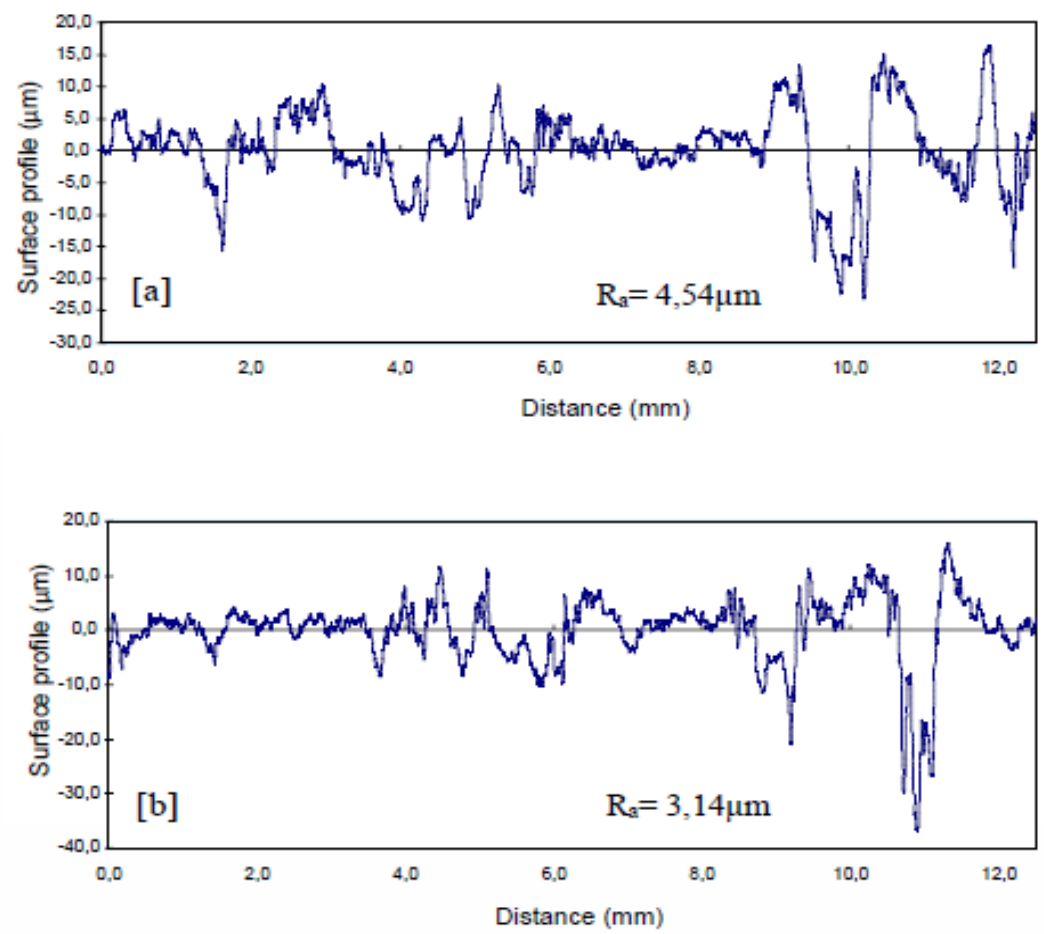

Figure 3: Surface profiles of $A$. auriculiformis wood before (a) and after (b) heat treatment at $180^{\circ} \mathrm{C}$ for $8 \mathrm{~h}$.

\section{Colour changes}

The colour variations were examined by means of amount of color difference before and after the thermal modification at different temperatures and durations under vacuum. Figure 5 shows the colour variations $(\Delta \mathrm{E})$ in wood heat treated at different temperatures for $8 \mathrm{~h}$ in vacuum. With increasing temperature of heat treatment, wood colour was seen dark brownish. The colour change was observed to be uniform though out the wood blocks. The mean colour values of wood heat treated at different temperatures were found to be significantly different $(\mathrm{F}=53,87 ; \mathrm{P}<0,001)$. Pairwise multiple comparisons (Tukey test) showed no statistically significant difference in colour of wood surface heat treated at 150 and $180^{\circ} \mathrm{C}(\mathrm{P}=0,167)$. 


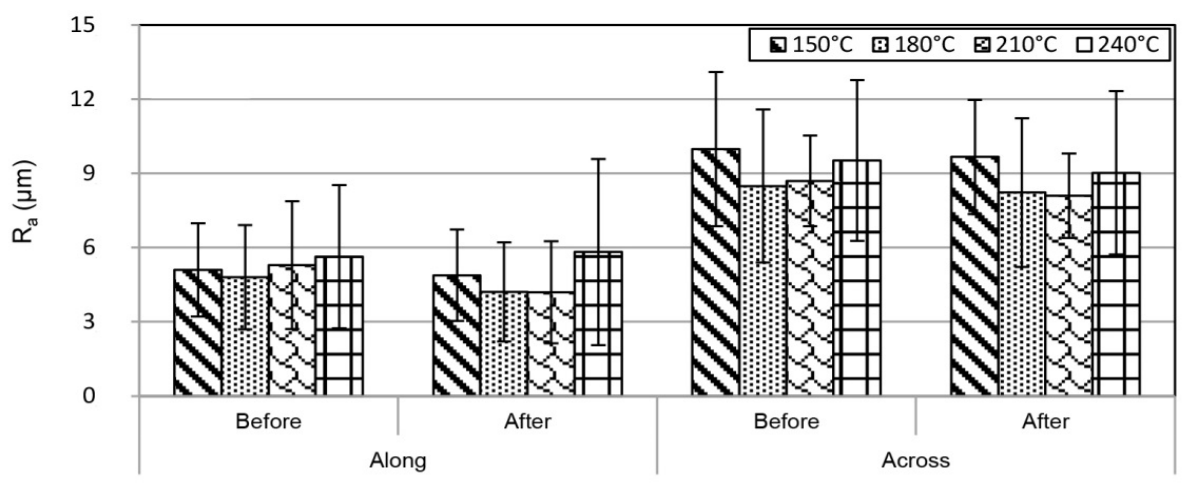

(a)

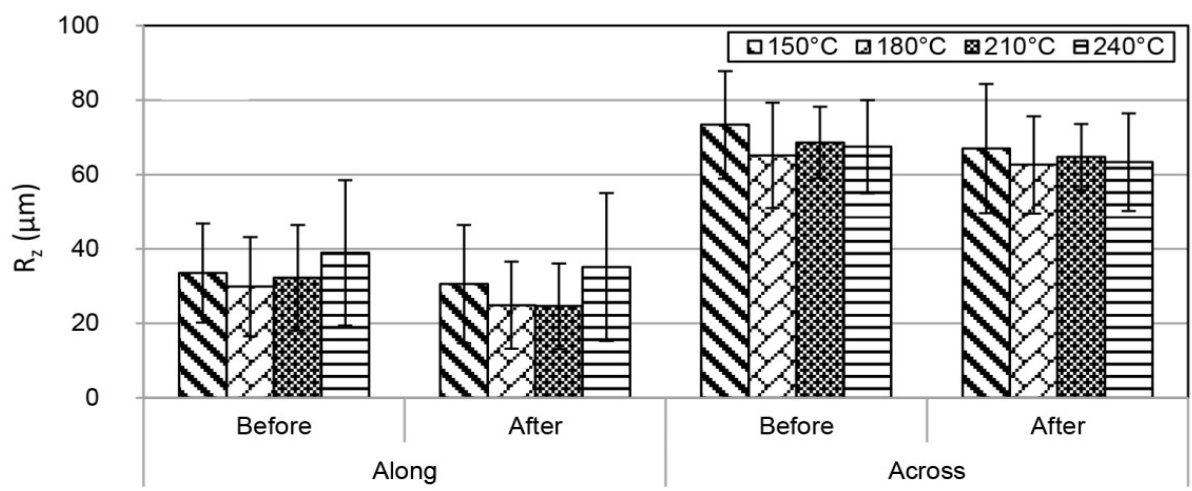

(b)

Figure 4: Average values of (a) $\mathrm{R}_{\mathrm{a}}$ and (b) $\mathrm{R}_{\mathrm{z}}$ of A. auriculiformis along and across the grain.

The observations on changes in colour are very important to evaluate the performances of wood towards colour acceptability, stability in various end-use applications. The colour of treated wood material was found to be uniformly changed throughout wood blocks. Increasing heat treatment temperatures have profound and variable effects on the colour changes of different wood species. With increasing treatment intensity, delta E-value was increased, showing that colour of wood surface became darker. However, no significant relationship between colour and other properties could be established. Depending on the severity of thermal modification process, the wood colour was changed from original to uniform dark brownish tones. Heat treated wood can therefore be successfully applied for wall paneling, siding, flooring tiles etc. due to its uniform colour change to darker, brownish colour, better moisture resistance and increased dimensional stability. It may be especially attractive to use heat treated Acacia wood for parquet flooring since it is possible to obtain different dark brownish colours of different shades by varying the process parameters (Emmler and Scheiding 2007).

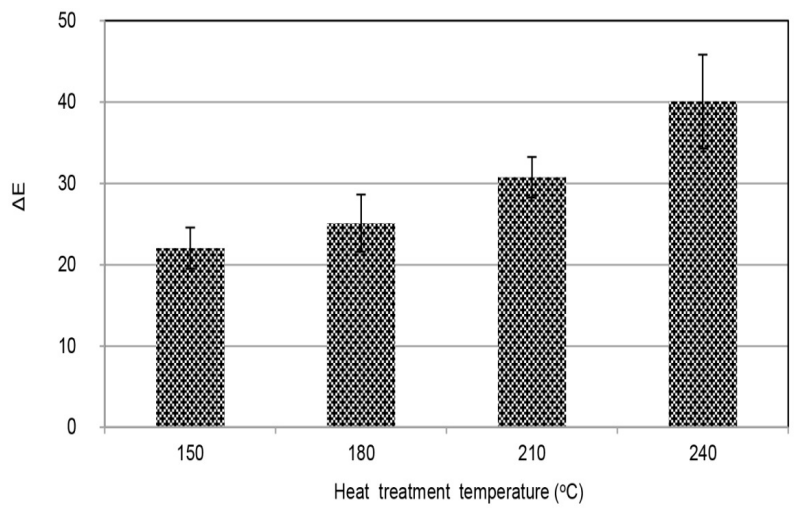

Figure 5: Colour variations $(\Delta \mathrm{E})$ in $A$. auriculiformis wood heat treated for $8 \mathrm{~h}$. 


\section{Flexural properties (MOR and MOE)}

Table 2 lists average values of flexural strength (MOR) and flexural stiffness (MOE) of $A$. auriculiformis wood heat treated at different temperatures along with standard deviations. Percentage of change compared to untreated wood is also given in the same table. Heat treatment temperature has significant effect on MOR $(\mathrm{F}=27,25 ; \mathrm{P}<0,001)$. There was no significant difference between MOR of untreated and wood heat treated at $150^{\circ} \mathrm{C}(\mathrm{P}=0,729)$ and $180^{\circ} \mathrm{C}(\mathrm{P}=0,136)$. The moderate reduction in MOR was noticed up to $210^{\circ} \mathrm{C}$ temperature while higher temperature of $240^{\circ} \mathrm{C}$ was found to be detrimental to flexural strength and MOR was reduced drastically compared to untreated control $(\mathrm{P}<0,001)$. MOE of heat treated wood was not much affected with increasing temperatures. A slight enhancement in average values of MOE was observed in wood samples thermally modified at $150^{\circ} \mathrm{C}$ and $210^{\circ} \mathrm{C}$. However, higher temperature of $240^{\circ} \mathrm{C}$ has affected the MOE significantly which was observed to be decreased by $14 \%$ compared to untreated control $(\mathrm{P}<0,001)$.

Variation of relative MOR of heat treated to untreated wood with weight loss (\%) due to heating process at different temperatures is shown in Figure 6. Some of the changes in the wood properties due to heat treatment such as strength are linked with various processes parameters (Hill 2006). The increase in the strength loss with increasing heat treatment temperature while MOE found to be rarely affected is also reported in the literature (Kubojima et al. 2000). The reduction in strength properties is mainly attributed to decrease in viscosity and plasticity of material (Kubojima et al. 2000). The degradation in strength has also been associated with changes in wood acidity (Hodgin and Lee 2002) while both strength loss and durability increases are reported to be closely related with the temperature and duration of heat treatment (Kim et al.1998). In general increased treatment intensity was found to affect the flexural strength of heat treated wood. Since the intensity of the treatment correlates with the colour of the wood it also can be generally followed that the darker the wood the lower the flexural strength (Hill 2006, Niemz et al. 2010).

Table 2: MOR and MOE of $A$. auriculiformis wood heat treated for $8 \mathrm{~h}$ under vacuum.

\begin{tabular}{|c|c|c|c|c|c}
\hline \multirow{2}{*}{$\begin{array}{c}\text { Flexural } \\
\text { properties }\end{array}$} & \multirow{2}{*}{$\begin{array}{c}\text { Untreated } \\
\text { wood }\end{array}$} & \multicolumn{4}{|c}{ Treatment temperatures } \\
\cline { 3 - 6 } & $\mathbf{1 5 0}^{\circ} \mathbf{C}$ & $\mathbf{1 8 0}^{\circ} \mathbf{C}$ & $\mathbf{2 1 0}^{\circ} \mathbf{C}$ & $\mathbf{2 4 0}^{\circ} \mathbf{C}$ \\
\hline MOR (MPa) & $111,6 \pm 10,7$ & $116,8 \pm 13,9$ & $100,9 \pm 13,1$ & $97,7 \pm 7,8$ & $44,3 \pm 6,5$ \\
\hline \% Change & - & 4,7 & $-9,6$ & $-12,5$ & $-60,3$ \\
\hline MOE (GPa) & $10,65 \pm 1,08$ & $11,21 \pm 1,70$ & $11,15 \pm 0,84$ & $12,11 \pm 1,39$ & $9,14 \pm 1,36$ \\
\hline \% Change & - & 5,3 & 4,7 & 13,7 & $-14,2$ \\
\hline
\end{tabular}

The changes in various properties are mostly influenced differently by the change of chemical parameters in different wood species (Windeisen et al. 2007, Windeisen et al. 2009). The bending strength is reported to be decreased in the hardwoods with increasing total phenol content. While heating up wood, the lignin is first softens, radicals are formed in the depolymerisation reactions that in turn are recombined to the chemical compounds of lower polarity. In this process, the hygroscopicity of lignin is found to decrease significantly (Tjeerdsma and Militz 2005, Windeisen and Wegener 2008). Transformation of lignin (i.e. increasing amounts on phenolic extractives in wood) seems to be closely correlated with decreased bending strength in hardwoods. A reduction in the hemicelluloses content is also found to be increased in total phenol concentration. During thermal degradation of hemicelluloses, the lignin-carbohydrate connections are also reported to be cleaved leading to the easier depolymerisation of this non-carbohydrate-bonded lignin fraction, yielding simple phenolic compounds. It seems that there is also a clear connection between a reduction in bending strength and hemicelluloses content. This establishes that in hardwoods, physical changes take place during degradation of hemicelluloses. Similarly, strong degradation of hemicelluloses through thermal treatment of wood has also been shown by several researchers (Pfriem and Wagenführ 2007). Understanding the varied behaviour of different types of wood elements during thermal treatment could therefore provide a basis for wood species dependent technology optimization in the future (Hofmann et al. 2008). 


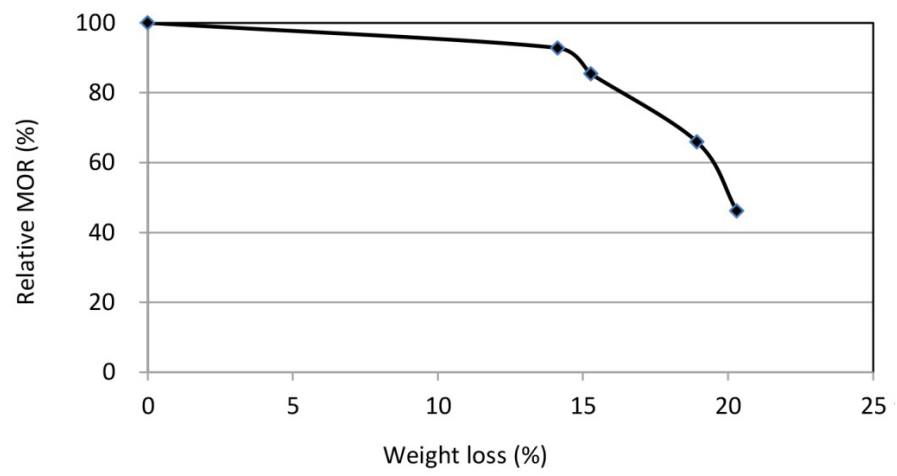

Figure 6: Variation of relative MOR of treated to untreated A. auriculiformis with weight loss.

\section{Decay resistance against fungi}

Unmodified and heat treated wood samples were degraded by white-rot (Coriolus versicolor) and brown$\operatorname{rot}$ (Polyporus meliae) fungi. Weight loss (WL) due to white and brown rot decay in heat treated and untreated wood is shown in Figure 7. It may be seen that untreated samples exhibited higher amount of WL against both decay fungi compared to heat treated wood blocks. Increasing intensity of heating temperatures has shown significant effect on the WL of wood blocks due to decay fungi. WL less than $10 \%$ was recorded in the wood blocks heat treated at $180^{\circ} \mathrm{C}$ and above for both the decay fungi. Compared to brown rot, higher amount of WL (\%) was recorded due to white rot decay in untreated wood samples. However, heat treated wood blocks exposed to brown rot showed lower amount of WL compared to white rot fungi. Wahab et al. (2012) also reported that oil-heat treatment was effective in reducing the attack of Acacia hybrid wood by G. trabeum, $P$. sanguineus and $C$. versicolors fungi. The percentage of weight loss was found to be decreased as temperature and duration increased.

Heat treatment of wood may be one of the most promising techniques to increase the decay resistance against decay fungi. It is well known that white rot of wood digest lignin rather than cellulose; while brown rot digests the cellulose, but leave lignin behind. Results showed different behaviour of resistance against white and brown rot fungi. Lignin is the least reactive wood component, but at high temperatures, bonds within the lignin complex will be cleaved, resulting in a higher concentration of phenolic groups (Kollmann and Fengel 1965). Some of the major reasons of improved durability of heat treated wood are: hydrophobic character of heat treated wood, generation of biocidal components, modification of wood polymers, degradation of hemicelluloses and reduction in cell wall porosity (Esteves and Pereira 2009, Kamdem et al. 2002, Niemz et al. 2010, Wahab et al. 2012). The reduction in average EMC contributes in retarding the rate of fungal attack (Metsa-Kortelainen and Viitanen 2010).

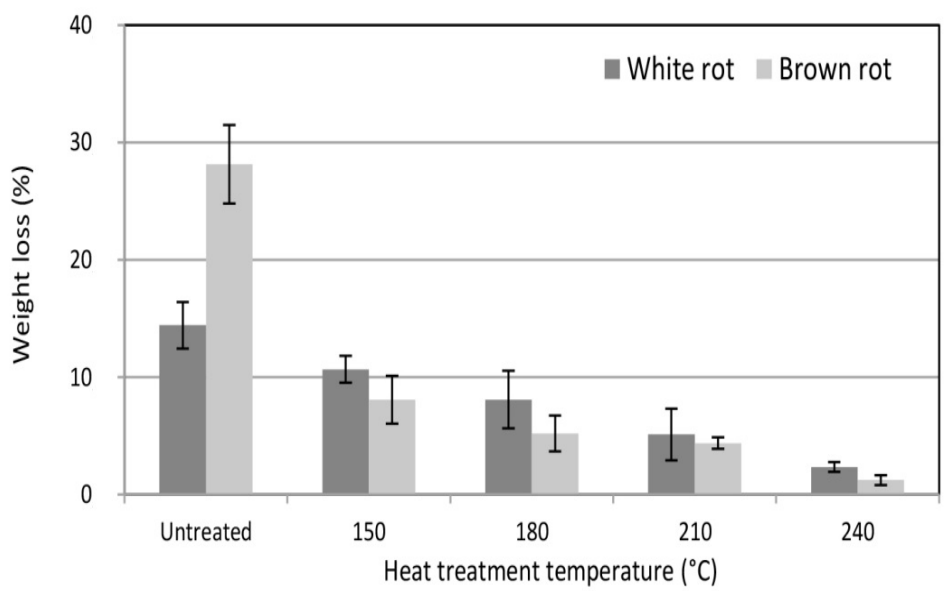

Figure 7: Weight loss due to white and brown rot fungi decay heat treated A. auriculiformis. 
Various chemical changes during heat treatment invariably lead to modification of various properties of wood (Windeisen et al. 2007, Windeisen et al. 2009). It was found that thermal modification is an eco-friendly process that turns wood dimensionally stable and darker in colour without using any hazardous chemicals. Heat treatment process is also found suitable for improving the decay resistance of low durability wood (Gerardin 2016). Information on outdoor durability of heat treated A. auriculiformis wood against termite attack is being collected and would be reported elsewhere. This would certainly help in bringing awareness for better utility and value-addition to fast growing plantation species an alternate wood resources by using thermal processing technique.

\section{CONCLUSIONS}

Plantation grown $A$. auriculiformis wood was subjected to different heat treatments under vacuum and various physical, mechanical and biological properties were evaluated. Density and shrinkage of wood were found to be reduced significantly after thermal modification. The anti-shrinkage efficiency was increased up to $65 \%$. Surface roughness parameters $\left(R_{a}\right.$ and $\left.R_{z}\right)$ were also observed to be reduced depending on thermal treatments. At different temperatures, $R_{a}$ values measured along the grain were significantly lower compared to across the grain. Changes in colour due to heat treatment are measured with colorimeter and found to be darkening with higher temperatures. The colour change was also observed to be uniform throughout wood. Flexural strength was found to decrease slightly with increasing treatment temperature up to $210^{\circ} \mathrm{C}$. Flexural stiffness (MOE) was not much affected by temperature up to $210^{\circ} \mathrm{C}$ while higher treatment temperatures were found to be deleterious for flexural strength and stiffness. Heat treated wood showed excellent decay resistance against brown and white rot fungi.Based on improved dimensional stability, colour, fungal decay resistance and certain other properties, A. auriculiformis wood may be used as an alternative to conventional timbers for various applications after moderate heat treatments below $210^{\circ} \mathrm{C}$ under vacuum. Thus, thermal modification provides an environmentally safe method of protecting sustainable timber species and offer a new generation of value-added wood material with enhanced stability and durability without using hazardous chemicals.

\section{ACKNOWLEDGEMENTS}

The author is grateful to the Director, IWST for his keen interest in this research work. Valuable help from technical staff in testing mechanical and biological properties is duly acknowledged. Author is also grateful to Indian Council of Forestry Research and Education (ICFRE), Dehradun for providing financial support in executing the research project.

\section{REFERENCES}

Indian standard. IS. 1986. Methods of testing small clear specimens. IS 1708-1986. Bureau of Indian Standards: New Delhi.

Indian standard. IS. 2008. Methods of laboratory testing of wood preservatives against fungi and borers (powder post beetles). Part 1: Determination of threshold values of wood preservatives against fungi. IS 48732008. Bureau of Indian Standards: New Delhi.

Ashaduzzaman, M.; Das, A.K.; Kayes, I.; Shams, M.I. 2011. Natural decay resistance of Acacia auriculiformis Cunn. ex. Benth and Dalbergia sissoo Roxb. Bangladesh Journal of Science and Industrial Research 46(2): 225-230.

Bakar, B.F.A.; Hiziroglu, S.; Tahir, P.M. 2013. Properties of some thermally modified wood species. Materials and Design 43: 348-355.

Chu, T.V. 2013. Improvement of dimensional stability of Acacia mangium wood by heat treatment: a case study of Vietnam. Journal of Forest Science 29(2):109-115.

Dwianto, W.; Inoue, M.; Tanaka, F.; Norimoto, M. 1996. The permanent fixation of compressive deformation in wood by heat treatment. In Proc. $3^{\text {rd }}$ Pacific Rim Bio-Based Composites Symposium, Kyoto, Japan. pp. 231-239. 
Emmler, R.; Scheiding, W. 2007. Darker shades of wood: Thermally modified timber (TMT) as a new material for parquet floorings. European Coatings Journal 4: 106-111.

Esteves, B.M.; Pereira, H.M. 2009. Wood modification by heat treatment: a review. BioResources 4(1): 370-404.

Gerardin, P. 2016. New alternatives for wood preservation based on thermal and chemical modification of wood-a review. Annals of Forest Science 73:559-570.

Gunduz, G.; Korkut, S.; Korkut, D.S. 2008. The effects of heat treatment on physical and technological properties and surface roughness of Camiyanı Black Pine (Pinus nigra Arn. subsp. pallasiana var. pallasiana) wood. Biores Technol 99:2275-2280.

Hill, C.A.S. 2006. Wood modification- chemical, thermal and other processes. John Wiley \& Sons, Chichester. $239 \mathrm{p}$.

Hodgin, D.A.; Lee, A.W.C. 2002. Comparison of strength properties and failure characteristics between fire-retardant-treated and untreated roofing lumber after long-term exposure: a South Carolina case study. $F_{O}-$ rest Products Journal 52(6):91-94.

Hofmann, T.; Retfalvi, T.; Albert, L.; Niemz, P. 2008. Investigation of the chemical changes in the structure of wood thermally modified within a nitrogen atmosphere autoclave. Wood Research 53 (3):1-14.

Inoue, M.; Norimoto, M.; Tanahashi, M.; Rowell, R.M. 1993. Steam or heat fixation of compressed wood. Wood and Fiber Science 25(3): 224-235.

Inoue, M.; Sekino, N.; Morooka, T.; Norimoto, M. 1996. Dimensional stabilization of wood composites by steaming I. Fixation of compressed wood by pre-steaming. In: Proc. $3^{\text {rd }}$ Pacific Rim Bio-Based Composites Symposium, Kyoto, Japan. pp. 240-248.

Kamdem, D.P.; Pizzi, A.; Jermanaud, A. 2002. Durability of heat-treated wood. Holz Roh Werkstoff 60 (1):1-6.

Kamdem, D.P.; Pizzi, A.; Triboulot, M.C. 2000. Heat-treated timber: potentially toxic byproducts presence and extent of wood cell wall degradation. Holz Roh Werkstoff 58(4):253-257.

Kawai, S.; Wang, Q.; Sasaki, H.; Tanahashi, M. 1992. Production of compressed laminated veneer lumber by steam pressing. In Proc. Pacific Rim Bio-Based Composites Symposium, pp. 121-128.

Kim, G.H.; Yun, K.E.; Kim, J.J. 1998. Effect of heat treatment on the decay resistance and the bending properties of radiata pine sapwood. Mater Organismen 32(2):101-108.

Kollmann, F.; Fengel, D. 1965. Anderungen der chemischen Zusammensetzung von Holz durch thermische Behandlung. Holz als Roh- und Werkstoff 23(12): 461-468.

Korkut, S.; Akgul, M. 2007. Effect of drying temperature on surface roughness of oak (Quercus petraea ssp. iberica (Steven ex Bieb) Krassiln) veneer. Building and Environment 42 (5):1931-1935.

Kubojima, Y.; Okano, T.; Ohta, M. 2000. Bending strength and toughness of heat-treated wood. Journal Wood Science 46(1):8-15.

Metsa-Kortelainen, S.; Antikainen, T.; Viitaniemi, P. 2006. The water absorption of sapwood and heartwood of Scots pine and Norway spruce heat-treated at $170^{\circ} \mathrm{C}, 190^{\circ} \mathrm{C}, 210^{\circ} \mathrm{C}$ and $230^{\circ} \mathrm{C}$. Holz Roh-Werkstoff 64:192-197.

Metsa-Kortelainen, S.; Viitanen, H. 2010. Effect of fungal exposure on the strength of thermally modified Norway spruce and Scots pine. Wood Mat Science and Engineering 5(1): 13-23.

Nakano, T.; Miyazaki, J. 2003. Surface fractal dimensionality and hygroscopicity for heated wood. Holzforschung 57: 289-294. 
Navi, P.; Girardet, F. 2000. Effect of THM treatment on the structure and properties of wood. Holzforschung 54:287-293.

Niemz, P.; Bekhta, P. 2003. Effect of high temperature on the changes in color, dimensional stability and mechanical properties of spruce wood. Holzforschung 57(5): 539-546.

Niemz, P.; Hofmann, T.; Retfalvi, T. 2010. Investigation of chemical changes in the structure of thermally modified wood. Maderas Cienc Tecnol 12(2):69-78.

Obataya, E.; Tanaka, F.; Norimoto, M.; Tomita, B. 2000. Hygroscopicity of heat-treated wood I: Effects of after-treatments on the hygroscopicity of heat-treated wood. Mokuzai Gakkaishi 46(2):77-87.

Obataya, E.; Tomita, B. 2002. Hygroscopicity of heat-treated wood. II Reversible and irreversible reductions in the hygroscopicity of wood due to heating. Mokuzai Gakkaishi 48(4):288-295.

Pfriem, A.; Wagenfuhr, A. 2007. Influence of thermally modification of spruce to unsteady-state sorption processes and wood moisture-dependent elasticity. In: Proc $3^{\text {rd }}$ European Conference on Wood Modification, $15^{\text {th }}-16^{\text {th }}$ Oct, Cardiff, UK pp. 367-373.

Rep, G.; Pohleven, F. 2001. Wood modification-a promising method for wood preservation. Drvna Industrija 52 (2): 71-76.

Repellin, V.; Guyonnet, R. 2005. Evaluation of heat-treated wood swelling by differential scanning calorimetry in relation to chemical composition. Holzforschung 59:28-34.

Shukla, S.R.; Rao, R.V.; Sharma, S.K.; Kumar, P.; Sudheendra, R.; Shashikala, S. 2007. Physical and mechanical properties of plantation grown Acacia auriculiformis of different ages. Australian Journal of Forestry 70 (2):86-92.

Shukla, S.R.; Sharma, S.K. 2014. Effect of high temperature processing under different environments on physical and surface properties of Rubberwood (Hevea brasiliensis). Journal of Indian Academy of Wood Science 11(2): 182-189.

Shukla, S.R.; Sharma, S.K. 2018. Effect of high temperature treatment of Hevea brasiliensis on density, strength properties and resistance to fungal decay. Journal of Indian Academy of Wood Science 15(1): 87-95.

Sundararaj, R.; Shanbhag, R.R.; Nagaveni, H.C.; Vijayalakshmi, G. 2015. Natural durability of timbers under Indian environmental conditions- An overview. International Biodeterioration \& Biodegradation 103:196-214.

Tjeerdsma, B.F.; Militz, H. 2005. Chemical changes in hydrothermal treated wood: FTIR analysis of combined hydrothermal and dry heat-treated wood. European Journal of Wood and Wood Products 63(2):102-111.

Wahab, R.; Khalid, I.; Tabet, T.A.; Mohamed, A.; Sulaiman, O.; Salim, R. Md.; Ayob, F.W. 2012. Effectiveness of hot oil treatment on cultivated 15 year-old Acacia hybrid against Coriolus versicolors, Gloeophyllum trabeum and Pycnoporus sanguineus. Sains Malaysiana 41(2):163-169.

Wikberg, H.; Liisa, M.S. 2004. Characterisation of thermally modified hard- and softwoods by $13 \mathrm{C}$ CPMAS NMR. Carbohydrate. Polymers 58: 461-466.

Windeisen, E.; Bächle, H.; Zimmer, B.; Wegener, G. 2009. Relations between chemical changes and mechanical properties of thermally treated wood. Holzforschung 63(6): 773-778.

Windeisen, E.; Strobel, C.; Wegener, G. 2007. Chemical changes during the production of thermo-treated beech wood. Wood Science and Technology 41(6):523-536.

Windeisen, E.; Wegener, G. 2008. Behaviour of lignin during thermal treatments of wood. Industrial Crops and Products 27(2):157-162. 